\title{
“O MESMO SAMBA": A PROFISSIONALIZAÇÃO DOS SAMBAS DE CACHOEIRA E SUA REIFICAÇÃO EM GRUPOS DE SAMBA DE RODA
}

\author{
Caio Csermak ${ }^{1}$ \\ Nina Graeff ${ }^{2}$
}

\begin{abstract}
Resumo: O reconhecimento nacional e internacional do samba de roda como patrimônio cultural imaterial acarretou em diversas investigações sobre suas consequências musicais e sociais. Um aspecto comumente levantado é o da profissionalização dos sambadores, que antes se encontravam espontaneamente em seu cotidiano no que chamaremos de "samba de vizinho", e que hoje se organizam nos "grupos de samba de roda": instituições musicais com nome, registro de integrantes, ensaios marcados, etc. Este aspecto será aprofundado neste artigo a partir da história e de etnografia do samba de Cachoeira (BA), cidade cujas características singulares implicaram em processos de comercialização de seus bens culturais significativamente precedentes à patrimonialização do samba. Buscamos, com isso, por um lado, demonstrar como a patrimonialização do samba não cria, mas intensifica e reifica processos que lhe são muito anteriores que, por outro lado, não necessariamente suprimem formas tradicionais de fazer samba na região. Pelo contrário, argumentamos que o "grupo de samba de roda" atua, já desde meados do século XX, como facilitador na transição entre os sambas do cotidiano e aquele das chamadas tocadas, apresentado como espetáculo em contextos extraordinários e cristalizado sob a categoria do "samba de roda".
\end{abstract}

Palavras-chave: samba de roda, Recôncavo Baiano, comercialização cultural, patrimônio cultural imaterial, música afro-brasileira.

\section{"THE SAME SAMBA": PROFESSIONALIZATION AND REIFICATION OF SAMBAS FROM CACHOEIRA, BAHIA, IN SAMBA DE RODA GROUPS}

\begin{abstract}
The national and international recognition of samba de roda as Intangible Cultural Heritage resulted in several investigations on its musical and social consequences. A common aspect approached is the
\end{abstract}

\footnotetext{
${ }^{1}$ Caio Csermak é doutorando do Programa de Pós-Graduação em Antropologia Social da Universidade de São Paulo em cooperação com a Universidade de Música Franz Liszt Weimar. Contato: caio.csermak@gmail.com

${ }^{2}$ Nina Graeff é doutora em Antropologia e Educação pela Universidade Livre de Berlim, pós-doutoranda do programa HONORS da mesma instituição e pesquisadora colaboradora da Universidade de Música Franz Liszt Weimar. Contato: info@ninagraeff.com.
} 
professionalization of samba, which used to be a spontaneous social gathering between neighbours (sambas de vizinho), and turned into organized samba de roda groups. musical institutions with name, registration of components, rehearsals, etc. This aspect will be thoroughly explored in this paper through a historic and ethnographic survey of the samba from Cachoeira (BA). The city's historic particularities reveal an early commercialization of its cultural goods that significantly precedes samba's heritagization. On the one hand, we seek to demonstrate how heritage making does not create, but intensifies and reifies processe, that, on the other hand, don't necessarily suppress traditional forms of samba. On the contrary, we argue that samba de roda groups act, since the mid 20th Century, as mediators in the transition between everyday sambas and the samba of tocadas, the one taking place in extraordinary contexts and becoming crystallized under the category of "samba de roda".

Key words: samba de roda, Recôncavo Baiano, cultural commodification, common cultural heritage, Afro Brazilian music.

\section{Introdução}

Os sambas do Recôncavo Baiano têm recebido significativa atenção acadêmica desde seu registro como Patrimônio Cultural Imaterial do Brasil pelo IPHAN $^{3}$ (2004) e como Obra-prima do Patrimônio Oral e Imaterial da Humanidade pela $\mathrm{UNESCO}^{4}$ (2005). Entre as causas e consequências investigadas deste processo, um aspecto recorrente é a institucionalização e profissionalização de grupos, abordado sobretudo como um processo recente e muito atrelado às medidas de salvaguarda ${ }^{5}$. Neste artigo pretendemos, a partir de material etnográfico ${ }^{6}$, desdobrar a profissionalização do samba ${ }^{7}$ da região. Para tanto, investigaremos primeiramente como ela remonta a

\footnotetext{
${ }^{3}$ Instituto do Patrimônio Histórico e Artístico Nacional.

${ }^{4}$ Organização das Nações Unidas para a Educação, a Ciência e a Cultura.

${ }^{5}$ Ver (BANDEIRA DE ALENCAR, 2010; GRAEFF, 2015; GRAEFF\&PINTO, 2012; TRINDADE DA SILVA, 2014; DÖRING, 2016; MARQUES, 2008; CSERMAK, 2017).

${ }^{6}$ Os dados aqui utilizados são de fontes variadas: revisão da literatura sobre o tema; entrevistas; gravações audiovisuais próprias e de terceiros; e dados coletados em nossas próprias experiências de campo na região do Recôncavo Baiano desde 2010 e, principalmente, desde 2015 no município de Cachoeira.

${ }^{7}$ Por profissionalização musical entendemos o processo pelo qual uma prática musical é formatada em um serviço passível de comercialização, o que geralmente implica na formação de grupos, sua institucionalização com coordenadoria, o estabelecimento de um repertório a ser oferecido e ensaiado com regularidade, etc.
} 
"O MESMO SAMBA":

A PROFISSIONALIZAÇÂOO DOS SAMBAS DE CACHOEIRA E SUA REIFICAÇÂOO EM GRUPOS DE SAMBA DE RODA

processos muito anteriores aos da patrimonialização, presentes já na década de 1950 na cidade de Cachoeira (CSERMAK, 2017).

Ao ampliar o escopo temporal da análise da profissionalização do samba $^{8}$ em Cachoeira, nossa intenção não é apenas de identificar suas consequências na prática do samba, no que tange especialmente à sua performance, mas também o que este processo pode revelar sobre a própria vida social da cidade. Não é casualidade que ele mostra uma maior intensidade em Cachoeira que em outras localidades do Recôncavo Baiano: ali gestou-se uma mercantilização das atividades culturais a longo prazo, na qual elementos cotidianos da cidade - como as fachadas dos casarios coloniais, os rituais de Candomblé e os sambas - passaram a integrar um catálogo de produtos e espetáculos passíveis de consumo por turistas, pesquisadores e moradores. Com isso, as manifestações culturais da cidade absorveram uma série de práticas consideradas profissionais.

A partir desse desdobramento histórico e etnográfico, torna-se possível questionar até que ponto a profissionalização do samba da região significa meramente uma contaminação da tradição por regimes externos de produção e difusão musical, cada vez mais presentes desde aquela época. Verificaremos se os regimes internos tradicionais também não contaminam o formato profissional do grupo de samba de roda, tratando-o como uma formatação de longa data de vários modos de fazer samba. Esta mútua contaminação certamente resulta em consequências de ordem musical, política e social para ambos os lados.

Entendendo tal formatação do fazer samba como um modo espetacularizado (CARVALHO, 2007; MACHADO SILVA, 2018) e "presentacional" (TURINO, 2008) da prática tradicional e "participatória" (op. cit.), distinguiremos uma da outra pelas categorias nativas da tocada e do samba de vizinho, respectivamente. Embora se influenciem mutuamente, trataremos ambas de maneira separada, como fazem os próprios tocadores de samba9. Tomaremos a fala de seu Carlito diferenciando os dois modos e afirmando que "em todos grupos tem o mesmo samba" como diretriz inicial e

${ }^{8}$ Tal fenômeno não se limitou ao samba, mas ocorreu com mais força nele.

${ }^{9}$ Neste artigo escolhemos utilizar os termos samba e tocadores de samba para designar as atividades cotidianas, ao passo que os termos samba de roda e sambador se referem a contextos institucionais e profissionalizados. Esta divisão é relevante, pois muitos sujeitos desta pesquisa não se consideram sambadores. 
condutora de nossa argumentação, para em seguida apresentar um breve histórico do desenvolvimento musical de Cachoeira. A fim de demonstrar as consequências de um longo processo histórico sobre as formas atuais de fazer samba, descreveremos os contextos de formação dos grupos de Cachoeira, para então analisar as principais diferenças formais e musicais entre as tocadas e os sambas de vizinho.

A partir dessas análises, refletiremos sobre o estatuto das categorias samba e samba de roda, contextualizando-o em meio a uma rede de relações entre pessoas, sujeitos coletivos e instituições que habitam o mundo dos tocadores de samba desde os momentos mais privados e/ou religiosos, até os eventos públicos e espetacularizados. Alinhados com a noção proposta por Carneiro da Cunha que diferencia as categorias de cultura sem aspas e cultura com aspas (2009), proporemos o samba de roda como um "metadiscurso reflexivo" (op. cit., 372) sobre as diversas formas de fazer samba no Recôncavo Baiano, que as sintetiza em uma forma palatável a públicos externos representada pelo grupo de samba de roda.

\section{"Em todos os grupos tem o mesmo samba"}

Uma das maiores referências do samba em Cachoeira é seu Carlito, com quase 80 anos de idade. Seu nome é uma espécie de consenso na cidade, especialmente quando se fala do seu domínio de uma grande variedade de sambas. No entanto, quem procurar seu Carlito nos palcos das festas populares da cidade não o verá tocando junto a nenhum grupo de samba de roda. Tampouco é fácil encontrá-lo pelas ruas: tendo há muitos anos o ofício de caseiro de uma propriedade colonial no bairro da Pitanga, na entrada da cidade, seu Carlito não é uma figura constante das ruas cachoeiranas. Por não figurar em projetos culturais, palcos e registros audiovisuais, seu Carlito passa frequentemente despercebido pelo grupo heterogêneo e crescente de curiosos que desejam conhecer o samba de Cachoeira.

Em um passado não muito distante, no entanto, seu Carlito fez parte de dois grupos de samba de roda: o Suerdieck, nos anos 1970 e 80; e o Esmola Cantada, nos anos 1990. Sua adaptação à formalidade dos grupos nunca foi completa: seu Carlito tocava e cantava no palco com microfones, mas não gostava de ensaiar. Para ele, samba não se ensaia. Mais que isso, a atuação dos grupos de samba de roda teria reduzido a diversidade de sambas na cidade: 
"O MESMO SAMBA":

A PROFISSIONALIZAÇÃO DOS SAMBAS DE CACHOEIRA E SUA REIFICAÇÃO EM GRUPOS DE SAMBA DE RODA

Isso [que estou cantando] chama chula de relativo, do tempo antigo. Esses sambas de agora que a negada canta, eu também canto (...), mas o samba de agora é corrido. Agora... Esse daqui que é o samba original, naquele tempo não tinha corrido (...). O corrido que tinha era aquele que a negada dizia, quando estava em cima da maré, que cantava êêe leva eu minha canoa lá pra Ilha da Maré. Aquele que é o samba corrido. Eu canto [o samba corrido], mas não vou não [nas tocadas], que eu não sei sambar esse tipo de samba não (...). Agora eles botaram samba de roda, mas naquele tempo era samba de relativo, samba de estivador, samba de canoeiro, aí mudaram pra esse nome de samba de roda (...). Mas o samba era samba de canoeiro, samba de relativo, samba de embarcadiço e samba de estiva, só estivador. O samba de estivador daquele tempo era um cavaquinho, uma viola, um berimbau e dois pandeiros, não é agora que é cinquenta pandeiros, duzentos berimbaus, duzentos timbaus. (...) Em todos grupos que o senhor vai aqui, tem um samba; o senhor vai no outro, tem o mesmo samba; daqui um pouco, o mesmo samba. (Entrevista em 26/09/2017, Cachoeira).

Seu Carlito, portanto, aponta a transição de um regime de pluralidade de tipos de samba para outro de homogeneidade no qual apenas um gênero de samba é tocado, o corrido. A este regime limitado, seu Carlito dá o nome de samba de roda, categoria usada pelo IPHAN, assim como pela grande maioria dos projetos culturais e registros audiovisuais, para designar justamente a diversidade de sambas existente no Recôncavo Baiano.

Esta aparente contradição pode nos dizer muito sobre as transformações musicais do samba e da vida social dos tocadores ao longo das últimas décadas. Não apenas porque ela nos mostra que o significado da categoria samba de roda está em disputa, mas porque ela aponta para a existência de dois conjuntos de práticas e discursos distintos: o primeiro é o regime ordinário do cotidiano, no qual o samba foi e segue sendo parte da vida familiar, vicinal e religiosa de Cachoeira, que, inspirados por dona Dalva Damiana, chamamos aqui de samba de vizinho. ${ }^{10} \mathrm{O}$ segundo é o regime extraordinário do espetáculo, no qual o samba se institucionaliza como um gênero musical passível de ser comercializado enquanto performance musical, fixado em ensaios, registros audiovisuais e inventariado como

${ }^{10}$ Disponível em http://culturadigital.br/arquivodalvadamianadefreitas/dalva-damiana-de-freitas/. Acesso em 02 ago 2018. 
patrimônio cultural imaterial e que corresponde aos eventos do universo do espetáculo, abrigados sob o termo tocada.

Com o intuito de identificar tanto os fatores internos quanto os externos dessa profissionalização e consequente diferenciação entre dois modos de fazer samba, e de compreendê-las dentro do contexto histórico da região, convém remeter-nos a um período consideravelmente mais amplo do que aquele em que o samba está registrado como patrimônio. Neste, Cachoeira se mostra como um locus privilegiado de análise, já que suas singularidades históricas denotam o desenvolvimento de um ambiente propício à profissionalização, com raízes mais profundas e consequências mais palpáveis que em municípios vizinhos.

\section{"O vapor de Cachoeira não navega mais"}

Em Cachoeira encontramos turistas negros estadunidenses em busca de suas raízes étnicas, pesquisadores interessados em um dos gêneros musicais com presença reconhecida na gênese da música popular brasileira, fotógrafos e cineastas que procuram a riqueza imagética desta cidade repleta de cores, reminiscências da África e casarios coloniais. Afinal, trata-se de uma das cidades que, no século XIX, figurou entre as mais ricas e importantes do estado da Bahia, pois localizada estrategicamente no coração da região produtora de cana-de-açúcar e no ponto navegável mais adentro do continente desde Salvador (BARICKMAN, 2003).

Naquela época, a navegação era o principal meio de transporte de pessoas e mercadorias entre a capital e o continente. Cachoeira se tornou o principal porto de uma rede de cidades e povoados surgidos ao longo das margens do rio Paraguaçu, as quais já eram relativamente povoadas em finais do século XVIII (IPHAN, 2006). A cidade era a principal ligação entre Salvador e o continente, entreposto comercial entre águas e terras, começo dos caminhos que levavam tanto ao sertão e ao Norte-Nordeste do Brasil, como ao Centro-Sul do país (MACIEL, 2001). Foi no ambiente cosmopolita do porto que a cidade cresceu em tamanho e importância, crescimento também capitaneado por dezenas de engenhos de cana-de-açúcar e poucas, porém importantes, fábricas de charuto, como a Leite Alves, a Dannemann e a Suerdieck. 
"O MESMO SAMBA":

A PROFISSIONALIZAÇÂOO DOS SAMBAS DE CACHOEIRA E SUA REIFICAÇÂOO EM GRUPOS DE SAMBA DE RODA

Nesse período efervescente se desenvolve uma elite intelectual que fundaria instituições culturais em moldes europeus na cidade, como as bandas filarmônicas Sociedade Cultural Orpheica Lyra Ceciliana (1870) e Sociedade Lítero Musical Minerva Cachoeirana (1878), ambas ainda em atividade. As filarmônicas são bandas marciais que funcionam como instituições conservatoriais de música, nas quais o ensino de música se baseia em métodos, repertório e notação musical europeus. Em Cachoeira, as filarmônicas foram responsáveis pela formação de centenas de músicos, entre os quais alguns sambadores.

Após a falência da indústria do açúcar em finais do século XIX, o Recôncavo Baiano entrou em um período de recessão econômica (FRAGA, 2014). No entanto, resquícios da vida cultural desta elite branca e letrada atravessaram o século XX, como a manutenção das bandas filarmônicas e os concertos das bandas de baile no suntuoso Hotel Colombo e no barco a vapor que transportava pessoas entre Cachoeira, Maragogipe e Salvador. Alguns tocadores de samba - como seu Pedro Galinha Morta - atuavam nessas bandas, tendo já aí se acostumado a um regime da música como espetáculo e mercadoria que, posteriormente, se estenderia ao samba.

O conjunto arquitetônico e paisagístico da cidade foi tombado em 1971, década em que o potencial turístico da cidade começou a ser explorado por empresários e pela Bahiatursa - Superintendência de Fomento ao Turismo do Estado da Bahia. Logo no ano seguinte ao tombamento, a Bahiatursa financiou a realização da primeira festa de São João de grande porte na cidade, um evento marcante para a profissionalização do samba (ROQUE DE CASTRO, 2012). Como estratégia para fomentar o turismo no interior do estado, o governo da Bahia transformou uma festa religiosa e vicinal, o São João, em um megaespetáculo apresentando músicos brasileiros renomados em palcos de grande porte (op. cit.). Logo no primeiro ano foram feitos shows de nomes nacionais, como Luiz Gonzaga, Marinês e Sua Gente e Sandro Becker. O formato de megaespectáculo do São João foi sendo paulatinamente absorvido pelas prefeituras e o governo do estado como um modelo para a organização de festas populares na Bahia (op. cit.).

A partir daquela época, o investimento público e a iniciativa privada intensificaram a transformação de Cachoeira em um polo turístico, o que foi facilitado pela proximidade de Salvador e de seu aeroporto internacional. Deste então, o calendário anual de festas de Cachoeira conta com diversos 
eventos em que órgãos públicos montam palcos pela cidade com uma programação combinando grupos locais e forasteiros de renome estadual e nacional. Na esteira deste processo, o turismo tornou-se uma das principais atividades rentáveis da cidade e um motor para a transformação do samba em espetáculo, um produto a ser consumido por turistas brasileiros e estrangeiros.

Além do turismo capitaneado pelo São João e pelo conjunto arquitetônico, Cachoeira começa a atrair visitantes interessados na riqueza cultural e na ancestralidade africana na cidade. Esse turismo étnico (VATIN, 2008) terá como principais elementos de interesse a Festa da Boa Morte e Glória, terreiros de Candomblé, comunidades quilombolas e os grupos de samba de roda - contratados desde os anos 1980 para se apresentar a turistas em hotéis e restaurantes, segundo nos informaram alguns tocadores. Neste cenário, aquele regime institucionalizado de música das filarmônicas e das bandas de baile começa a tomar conta do samba, até então restrito, como apontou Waddey (1980), à dimensão da vida doméstica e religiosa.

Nos anos 2000, este processo se intensifica devido a dois fatores fundamentais. O primeiro diz respeito à implementação da nova agenda nacional de políticas e eventos culturais durante os governos Lula (2003-2010) (RUBIM, 2010), na qual se inserem as políticas de proteção e promoção do patrimônio cultural imaterial. Este fato aprofundou o perfil de polo cultural do município, assim como intensificou a reificação das manifestações culturais locais como um objeto de políticas e projetos culturais. Já o segundo fator foi a abertura, em 2006, de um dos campi da Universidade Federal do Recôncavo da Bahia em Cachoeira, com a oferta de cursos como Artes Visuais, Cinema, História e Ciências Sociais. A abertura da universidade e o impacto causado pela chegada de alunos, professores e pesquisadores das humanidades e artes para a cidade fomentou a produção de registros audiovisuais e a realização anual de diversos festivais e encontros de variadas linguagens artísticas, transformando a cidade em um dos polos culturais da Bahia.

Cachoeira foi uma cidade rica e cosmopolita no século XIX que perdeu relevância política e econômica ao longo do século XX. Enquanto as demais regiões do Recôncavo Baiano encontraram outras matrizes de renda e visibilidade política na indústria e no comércio, Cachoeira o fez nos setores de 
"O MESMO SAMBA":

A PROFISSIONALIZAÇÂOO DOS SAMBAS DE CACHOEIRA E SUA REIFICAÇÂOO EM GRUPOS DE SAMBA DE RODA

turismo e cultura. Não nos surpreende que estas áreas estejam sob gestão da mesma secretaria na Prefeitura Municipal. Sendo assim, quando ocorrem os registros nacional e internacional do samba de roda como patrimônio cultural no começo dos anos 2000, a profissionalização do samba e a organização dos tocadores em grupos já estavam sedimentadas em Cachoeira. Como, então, formou-se este processo e como ele se relaciona com a patrimonialização?

\section{Contextos de formação dos grupos de samba de roda de Cachoeira}

O primeiro grupo de samba de roda criado em Cachoeira foi o Samba de Roda da Suerdieck, fundado por dona Dalva Damiana de Freitas. Nascida em 1927, dona Dalva atuou como operária da indústria fumageira por décadas, primeiramente na fábrica de charutos de luxo Dannemann e, posteriormente, na Suerdieck. Foi nesta que ela organizou, em 1958, o Samba de Roda da Suerdieck, formado por operárias e operários da fábrica. Podemos considerar a organização do grupo como marco fundacional da profissionalização do samba em Cachoeira, criando um regime de ensaios, formação fixa e figurinos.

O grupo de dona Dalva começa a operar a transição do samba de vizinho como acontecimento informal do espaço doméstico, para o samba de roda, organizando-se para sair ao espaço público através das tocadas apresentações de regime profissional. Segundo dona Dalva, antes da organização de seu grupo o samba acontecia

(...) dentro de casa, quando terminava aquela festinha, qualquer coisa, fazia aquele sambinha, aquela roda, aquela coisa, ficava dentro de casa, mas não era nada atualizado para o povo saber não (...) sambinha, tomava aquele licorzinho - já vou, até amanhã! Até amanhã! Pronto, acabou. Mas pra hoje em dia ser reconhecido, com a grande quantidade de sambadores que o mundo hoje apresenta, eu, Dalva Damiana de Freitas, trouxe o samba pra rua pro pessoal conhecer e ver, e acreditar que o samba de roda é cultura, samba de roda faz parte da vida da gente. (Entrevista em 08/02/2017, Cachoeira)

O samba era característico do âmbito doméstico, o que, no caso de Cachoeira, não quer dizer, necessariamente, o interior de residências. Como nos mostra Louis Marcelin (1999), o espaço da residência no Recôncavo Baiano se projeta para a rua. Neste sentido, o samba de vizinho, este samba de dentro de casa a que alude dona Dalva, era também feito na rua - pensada como uma 
extensão da casa. Ao passo que trazer "o samba pra rua" refere-se a trazê-lo ao espaço público, de domínio da elite branca cachoeirana: as instituições do Estado, as festas cívicas, a fábrica e os espetáculos de música.

A apropriação de formas de organizações sociais brancas por parte das camadas negras do Recôncavo Baiano é recorrente em sua história. No século XIX, por exemplo, as irmandades de leigos da Igreja Católica foram essenciais para promover uma forma legalizada de organização social e mútua assistência para negros libertos e escravizados (MARQUES, 2008). A organização do Samba de Roda da Suerdieck é um primeiro movimento de ocupação destes espaços pelo samba que, não por acaso, toma a forma de um grupo artístico. De acordo com a liderança política Valmir da Boa Morte, dona Dalva

\begin{abstract}
Começa então a fazer essa organização que não é a orquestra das filarmônicas, não é a orquestra de Tranquilino Bastos, mas é a orquestra de dona Dalva Damiana de Freitas. Porque ela começa a organizar isso e quando ela resolve tirar isso de dentro da fábrica e levar isso pras ruas, vira espetáculo, vira atração. Coisa de negro nunca foi espetáculo, coisa de negro era vagabundagem, coisa de negro era coisa de preto, era "não se ouve, não se vê, não se fala, isso não se canta", entendeu? Tudo dentro daquele campo ainda, daquele universo ainda de preconceito, de racismo, de diferença, né? Mas, no entanto, dona Dalva, ela consegue trazer a força do seu trabalho, da sua resistência, do seu empoderamento, da sua forma de vida para o palco. (Entrevista em 07/02/2017, Cachoeira)
\end{abstract}

Valmir faz uma diferenciação entre o contexto da música feita pelas orquestras filarmônicas - do espetáculo - e o daquela feita pela população negra - vítima de preconceito. Nesse âmbito público da elite branca, o samba passa a ocupar um novo espaço e a operar em um novo regime discursivo, o do espetáculo. Assim, a transformação do samba em um espetáculo não representa apenas uma apropriação do samba pelo mercado cultural e turístico, mas também uma luta por visibilidade e oportunidades políticas e econômicas do povo negro de Cachoeira.

Em 1972, o Samba de Roda da Suerdieck é contratado para se apresentar no primeiro São João espetacularizado da cidade, o "São João Feira do Porto". A equipe da Bahiatursa tinha o objetivo de propiciar um caráter local para a festa, convidando grupos da cidade a compor a programação 
"O MESMO SAMBA":

A PROFISSIONALIZAÇÂOO DOS SAMBAS DE CACHOEIRA E SUA REIFICAÇÂOO EM GRUPOS DE SAMBA DE RODA

musical ${ }^{11}$. A escolha recaiu sobre o samba e, neste contexto, o grupo de dona Dalva era o único com uma organização mais formal. É aí que o samba de roda começa a integrar a programação do São João anualmente, incentivando a organização de outros tocadores de samba em grupos para serem contratados para a festa, e, da mesma forma, a contratação destes grupos por parte da prefeitura e de donos de hotéis e restaurantes para demais eventos do município.

Ao observarmos o histórico de criações de grupos de samba a partir desta época, percebemos que o aumento de oportunidades remuneradas de apresentação relaciona-se diretamente com a organização de grupos de samba. É ainda no final dos anos 1970 que o Samba de Roda Filhos de Nagô é criado em São Félix, cidade vizinha, por amigos que tocavam para turistas e locais. Nos anos 1980 ocorre uma série de fundações de grupos na cidade ${ }^{12}$, que diminui nos anos $1990^{13}$ e volta nos anos subsequentes à patrimonialização do samba (2004-2005). Neste último período, é interessante notar que as fundações atingem também as áreas rurais e os distritos de Santiago do Iguape e São Francisco do Paraguaçu.

\section{As tocadas e os grupos de samba de roda}

Essas novas oportunidades de apresentação remunerada correspondem à categoria local de tocada: apresentações musicais de samba, geralmente em palcos, com amplificação de vozes e instrumentos nas quais há uma separação entre músicos e público. Os tocadores diferenciam as tocadas daqueles eventos em que o samba acontece de maneira espontânea ou por obrigação religiosa. Tocadas são compromissos profissionais mediante o pagamento de cachê, escambo por objetos - especialmente equipamentos sonoros - ou troca de favores. Seus contextos são diversos, acontecendo em festas públicas organizadas pela prefeitura municipal e pelo governo do estado; festas religiosas de grande porte; festivais e eventos culturais

\footnotetext{
11 Antônio Moraes Ribeiro, ex-secretário da cultura de Cachoeira que participou da organização da primeira festa de São João da cidade. Entrevista em 23/03/2018, Cachoeira.

12 É o caso do Samba de Roda Filhos da Barragem, Samba de Roda Amor de Mamãe e Samba de Roda Filhos do Caquende.

13 Valmir da Boa Morte cria o Samba de Roda Filhos do Paraguaçu, de curta existência, e o Samba de Roda Esmola Cantada da Ladeira da Cadeia é organizado em torno dos devotos do bairro da Ladeira da Cadeia.
} 
organizados por associações culturais e por empresas do setor da cultura; eventos para turistas em hotéis e outros espaços; ou ainda apresentações particulares na casa de personagens da elite cachoeirana, como políticos e grandes comerciantes.

Convém delimitar o que é a categoria local de grupo de samba de roda atualmente, embora, claro, exista uma variedade grande de formas de organização. Um grupo de samba de roda é uma instituição musical com nome, coordenador ou presidente, figurino, um repertório razoavelmente fixo e uma formação de 12 a 25 sambadores, também fixa, mas com uma série de sambadores substitutos. A instrumentação mais comum de um grupo de samba de roda de Cachoeira contém tabuinhas (dois pedaços de madeira percutidos um contra o outro), pandeiros, timbal ou atabaque, tamborim, prato-e-faca ou reco-reco, triângulo, maraca, viola de dez cordas, cavaquinho, violão ou baixo elétrico e "105" (surdo). Os dois últimos são exemplos da inserção de novos instrumentos na tradição, como resultado do novo regime profissional dos grupos (GRAEFF, 2015).

Os grupos de samba de roda realizam ensaios, alguns esporadicamente e outros com mais regularidade. O mais comum é que os ensaios se concentrem na véspera de alguma tocada importante ou de algum registro audiovisual, mas, geralmente, não se ensaia antes de tocadas de pequeno porte. Os ensaios são mais um encontro dos sambadores do grupo onde se toca sem qualquer planejamento os sambas de seu cotidiano. Eventualmente uma nova composição de um dos componentes do grupo é agregada ao repertório tradicional de domínio público. No entanto, não há necessidade de se criar um arranjo; o novo samba sempre será enquadrado dentro da estrutura musical dos outros sambas sendo, em Cachoeira, cantado exclusivamente na tonalidade de Sol maior, independente da extensão vocal do cantador. Assim, não se ensaia um espetáculo com uma narrativa prédeterminada e cujas obras de execução mais complexa são repetidas até que todos as dominem, como é o caso na música popular.

Um ensaio é antes um encontro de amigos que fazem samba: sempre há comida, cerveja, risadas e fofocas. Vizinhos podem entrar e começar a sambar junto. Frequentemente há alguém indo e voltando com cervejas e copos de plástico de um bar próximo. O feijão é esquentado no fogo e repartido com muita farinha entre todos os presentes. Um transeunte 
"O MESMO SAMBA":

A PROFISSIONALIZAÇÂOO DOS SAMBAS DE CACHOEIRA E SUA REIFICAÇÂOO EM GRUPOS DE SAMBA DE RODA

desavisado pensa se tratar de uma festa - e não está enganado, sendo logo convidado a entrar. O ensaio, muitas vezes, acaba por se tornar uma pequena festa.

Como podemos ver no caso de Cachoeira, as políticas de patrimônio cultural imaterial não foram responsáveis pela criação de um modelo de grupo de samba de roda, mas geraram, sim, um ambiente de intensa criação de grupos, privilegiando esta forma de organização social. Afinal, ela corresponde à necessidade do Estado por sujeitos coletivos institucionalizados, para que se possa dialogar, negociar e transferir recursos financeiros a eles. Neste sentido, tem se tornado comum, desde os anos 2000, o registro dos grupos de samba de roda como pessoas jurídicas na forma de associações culturais. Este é um aprofundamento do processo de organização dos grupos que foi fomentado não apenas pela patrimonialização do samba de roda, mas também pela execução de novos projetos e políticas culturais, já que, em muitos casos, a existência de uma pessoa jurídica é uma condição para a celebração de contratos.

Por outro lado, a chancela criada pelo título de patrimônio cultural imaterial aumentou consideravelmente o potencial de sucesso para projetos que tivessem o samba de roda como objeto. Sabe-se que os governos locais e as organizações internacionais comprometidas com a proteção e promoção do patrimônio cultural imaterial operam sob a pressão de apresentar resultados mensuráveis, mas como fazê-lo quando os sujeitos coletivos que são objetos de suas políticas e projetos têm existência instável e pouco institucionalizada?

Não foi casualidade que um dos primeiros atos do registro do samba de roda como patrimônio cultural imaterial do Brasil pelo IPHAN tenha sido a criação de uma pessoa jurídica para representá-lo, a Associação dos Sambadores do Estado da Bahia - ASSEBA ${ }^{14}$. A ASSEBA foi criada como uma instituição representativa regional em um contexto que a maioria dos sambadores não mantinha relações sociais com outros tocadores ou grupos para muito além dos limites do seu município (SANDRONI, 2010). A criação da ASSEBA mostrou que, para levar a cabo um conjunto de políticas públicas para o samba de roda, o Estado brasileiro precisava criar um sujeito coletivo com pretensa capacidade de representação do samba de roda como um todo.

\footnotetext{
${ }^{14}$ A ASSEBA é formada, por sua vez, por outras associações locais de menor porte e, em última instância, por grupos de samba de roda
}

Pontos de Interrogaçầo, v. 8, n. 2, jul.-dez., p. 27-50, 2018. 
A ASSEBA passou a representar o samba enquanto uma cadeia institucional de associações com personalidade jurídica e grupos de samba de roda com existência formal, os quais passavam a ser registrados pela associação. É justamente este contexto de institucionalização que, a partir dos anos 2000, fomentou a criação de uma série de novos grupos de samba de roda. Esta criação, contudo, se deu nos moldes que, no caso de Cachoeira, já vinham se desenhando desde os anos 1950.

Os grupos possuem uma existência virtual que se materializa em tocadas e outras ocasiões esparsas - como a gravação de um CD ou documentário. Assim, se alguém vai a Cachoeira com o objetivo de conhecer um grupo específico de samba de roda, pode levar meses para encontrá-lo materializado em uma tocada. Entretanto, será muito provável encontrar os seus componentes fazendo samba no bar da esquina, num toque de Candomblé no próximo fim de semana ou no caruru na casa de um vizinho. Isso acontece porque o grupo de samba de roda é uma institucionalização de um regime cotidiano de relações familiares e comunitárias ${ }^{15}$.

O grupo de samba de roda representa, portanto, apenas uma das formas possíveis de organização social de coletivos afrocachoeiranos. No palco, juntam-se a ele famílias, comunidades religiosas e de bairros. A concepção local de um grupo artístico profissional de samba de roda envolve de quinze a trinta pessoas, resultando em uma redução de possibilidades de apresentação em outras cidades e estados pelo alto custo de transporte e em divisões de cachês que geram valores não raro irrisórios para cada sambador. Assim, percebemos que a lógica endógena de organização social se sobrepõe à externa de comercialização, que, em busca do lucro, pressupõe bandas de poucos músicos e maior rentabilidade por integrante. O que é transferido para o palco não é um gênero musical feito por profissionais da música, mas o próprio samba enquanto evento inclusivo e aberto a todos.

\footnotetext{
15 Por exemplo, os sambadores do Samba de Roda Filhos do Caquende são parentes consanguíneos ou vizinhos do bairro do Caquende, muitos deles filhos-de-santo do mesmo terreiro de Candomblé; o Samba de Roda Esmola Cantada é formado por devotos da Santa Cruz, também parentes ou vizinhos do bairro da Ladeira da Cadeia; o Samba de Roda de Dona Dalva já apresenta uma distribuição heterogênea de sambadores por bairros de Cachoeira e cidades próximas, mas se organiza a partir do núcleo familiar de dona Dalva, e assim por diante.
} 
"O MESMO SAMBA":

A PROFISSIONALIZAÇÂOO DOS SAMBAS DE CACHOEIRA E SUA REIFICAÇẪO EM GRUPOS DE SAMBA DE RODA

\section{A formatação de sambas de vizinho em tocadas}

O samba faz parte de diversos acontecimentos de Cachoeira, desde os mais espontâneos até as tocadas. O que chamamos de samba de vizinho não necessita de motivo ou planejamento prévio, basta que algumas pessoas se juntem e comecem a bater palmas, cantar e dançar para que o samba aconteça. Ele também pode acontecer em ocasiões planejadas tradicionais, como em Candomblés, rezas de santo e carurus. Considerados por tocadores na faixa etária entre 50 e 70 anos como os principais eventos de samba de sua juventude, tomaremos os carurus como exemplo de transição entre os modos samba de vizinho tocada.

Caruru designa uma festa religiosa onde se oferece a comida votiva que lhe dá o nome. Carurus são oferecido em diversos momentos do ano para santos e orixás, em comemoração a aniversários ou como agradecimento a alguma graça alcançada. O mês em que mais se realizam carurus é setembro, em homenagem ao dia de São Cosme e São Damião, também reconhecidos como os orixás gêmeos Ibejis. Porque o caruru é uma oferenda de alimento partilhada comunitariamente, ele se torna uma festa na qual a presença do samba é obrigatória e não raro atravessa a madrugada.

Uma diferença substancial apontada pelos mais velhos entre carurus antigos e atuais é que a performance musical do samba teria se tornado menos espontânea. Se antigamente tocadores de famílias e bairros distintos se encontravam em um caruru sem uma formação de músicos oficial, revezando-se nos instrumentos, cantos e dança, hoje em dia é muito comum que um grupo de samba de roda seja chamado para tocar em um caruru. Nesses casos, os grupos vão aos carurus com formações menores do que a dos palcos das festas oficiais, já que os carurus acontecem, geralmente, em residências. Na maioria dos casos, os grupos não cobram cachê, por entenderem os carurus como uma obrigação religiosa ou comunitária. É também comum que demais presentes nos carurus se revezem com os tocadores do grupo. Os que fecham a roda batendo palmas, cantando no coro e dançando continuam sendo, como antigamente, partes essenciais da performance nos sambas de vizinho, já que na música afro-baiana do Recôncavo Baiano a tríade tocar-cantar-dançar é inseparável (DÖRING, 2016).

Ainda assim, a formalidade do convite e/ou da contratação de um grupo de samba de roda para um caruru faz com que os sambadores veteranos 
enfatizem sua diferença em relação aos carurus do tempo antigo, onde todos chegavam e tocavam sem organização prévia. Ademais, sambadores mais velhos como Pedro Galinha Morta, Zel do Samba e seu Nascimento, afirmam que nos carurus do passado utilizavam-se apenas de palmas, pandeiros, viola e timbal, sem violão, cavaquinho ou percussões graves, quanto menos amplificação.

Nas tocadas de hoje em dia, desfaz-se a circularidade social formada pela interação entre tocadores e dançarinos de samba na roda. Enquanto nos sambas de vizinho todos são potenciais tocadores e/ou dançarinos, no palco entram apenas aqueles com filiação a um grupo de samba de roda. Mesmo que no cotidiano seja comum a distinção entre virtuosos tocadores e tocadores comuns, é apenas no contexto das tocadas que passa a existir a ideia de músico profissional, como ilustra a fala de seu Nascimento, integrante do Samba de Roda Esmola Cantada da Ladeira da Cadeia:

No palanque a responsabilidade dobra. No samba antigo todo mundo ia e cantava e no palanque é diferente: é só um cantando. Antigamente era só goela, a gente sambava a noite toda. Hoje não; hoje tem que ter o cidadão em cima do palanque, sabendo se apresentar. De trinta anos pra cá mudou, o samba cresceu muito. (Entrevista em 25/01/2017, Cachoeira, grifo nosso)

Seu Nascimento, ao diferenciar os contextos de antigamente dos sambas de vizinho dos das tocadas atuais, evoca a ideia de que, no palco, o tocador tem uma responsabilidade maior, devendo "saber se apresentar". Assim, ele demonstra como a partir das tocadas se estabelece uma nova distinção entre músico profissional - com responsabilidade e habilidade em se apresentar - e amador, assim como entre a nova categoria do músico sambadore o público não-músico.

“Antigamente era só goela" porque não havia microfone e, não por acaso, usava-se o verbo gritar em vez de cantar, já que o cantador precisava se sobrepor sem microfone à projeção sonora de todos os outros instrumentos, palmas e vozes (GRAEFF, 2015). Já no palanque, amplifica-se tanto as vozes quanto os instrumentos. Eventos de samba que não o façam - em contexto profano ou sagrado - são cada vez mais raros. Esta prática de sonorização foi tomando conta dos grupos de samba de roda, tornando-se uma estética quase 
"O MESMO SAMBA":

A PROFISSIONALIZAÇÂOO DOS SAMBAS DE CACHOEIRA E SUA REIFICAÇÂOO EM GRUPOS DE SAMBA DE RODA

obrigatória que altera a mixagem orgânica de vozes, palmas e instrumentos e que transforma timbres e técnicas de canto e toque (GRAEFF, 2015; 2016).

Além disso, se nos sambas de vizinho toca-se por um tempo indefinido sem intervalo, no palco os sambas são organizados em pout pourris, blocos de canções que duram de vinte a trinta minutos. Se os sambas de vizinho podem se alongar por muitas horas e atravessar a madrugada, as tocadas duram cerca de noventa minutos. É queixa recorrente entre os tocadores mais velhos esta redução na duração dos eventos de samba, que ocorre tanto nas tocadas, quanto nos carurus. Com isso, vemos que os eventos profissionais do samba passam a influenciar e causar transformações também nos eventos cotidianos e sagrados (cf. GRAEFF, 2016) dos sambas de vizinho.

Ao colocar um palco em um espaço público da cidade, o poder público estabelece um território distinto do tradicional e comunitário, o da espetacularização das festas populares. Nele concentra-se um grande público em um espaço fixo defronte ao palco, cuja maior parte das atrações consiste de grupos em voga na mídia estadual, recebendo cachês muitas vezes acima dos cem mil reais ${ }^{16}$. Ao passo que, nos horários pouco nobres da tarde, quando o sol e o calor afugentam a maior parte do público, apresentam-se os grupos de samba de roda com cachês que variam entre mil e três mil reais.

Durante o espetáculo, os sambadores se organizam em uma ou duas linhas em um palco, também denominado localmente de palanque, elevado acima do chão. A separação que o palco estabelece com o chão é uma questão relevante: se nos terreiros de Candomblé e em muitos sambas de vizinho a conexão dos pés, geralmente descalços, com o chão permite uma troca de energia das pessoas com seu território, bem como entre si por estarem no mesmo plano, o palanque cria um terreno em separado, um país estrangeiro autorizado somente aos sambadores profissionais. Nessa lógica territorial do palco, as cordas, vozes principais e de resposta e percussões leves formam uma linha à frente, ao passo que as percussões mais graves ocupam a linha de trás. Mesmo nos grupos de samba de roda que se apresentam com baianas ou

\footnotetext{
${ }^{16}$ Nos festejos do São João Feira do Porto 2018 de Cachoeira, por exemplo, a dupla Simone e Simaria recebeu $\mathrm{R} \$ 350.000,00$ pelo cachê de um show. https://doem.org.br/ba/cachoeira/diarios/previsualizar/1oN7Ldak?filename=DOE-ba cachoeira-ed.209ano.632.pdf\& $c b=20180510155224$. Acesso em 11 ago 2018.
} 
sambadeiras, as dançarinas ficam em cima do palco, sambando em uma terceira linha à frente dos sambadores. Sambadores e público são separados por ainda mais duas linhas: a linha dos PAs, dos alto-falantes voltados para o público; e a linha dos monitores de palco, que dão o retorno do áudio que orienta os músicos em sua performance. Ainda que no público se formem rodas de dança, elas se encontram separadas dos sambadores. O palanque do espetáculo constitui, portanto, o território domesticado do palco, ao qual os sambadores têm que se limitar e que causa um corte transversal no território circular do samba, desfazendo justamente a característica que o distingue através do sufixo de roda (GRAEFF, 2016).

\section{Do samba ao samba de roda}

Embora localmente coexistam em Cachoeira diversas formas de organização social para executar sambas de vizinho e tocadas, os grupos que as engendram tornaram-se a face mais conhecida dos sambas da região, ao menos fora de seu contexto local. Estado e mercado cultural não negociam nem contratam sambas de vizinho para se apresentarem em determinados eventos, mas, sim, a instituição que os representa, referida como "grupo de samba de roda". É fora do contexto local que os diversos sambas necessitam de uma categoria capaz de diferenciá-los de outros sambas, principalmente em contraste aos do Rio de Janeiro, designando-os como samba de roda e tomando a roda como sua característica distintiva (GRAEFF, 2016).

Ainda que não seja possível afirmar com exatidão quando e como surgiu a categoria samba de roda, importa-nos refletir sobre o seu uso pelos tocadores de samba e sobre a maneira como foi apropriada pelos discursos do patrimônio cultural imaterial, especialmente pelo seu papel de guarda-chuva (DÖRING, 2016), isto é, de abarcar uma diversidade grande de gêneros musicais e eventos dentro de uma mesma categoria. É interessante notar que, no cotidiano, os tocadores raramente usam a categoria samba de roda, mas apenas samba, ou os termos relativos a estilos mais específicos como corrido, barravento ou chula. A maioria dos grupos de Cachoeira possui em seu nome o prefixo samba de roda, apontando uma estreita ligação entre esta categoria e a função profissionalizada da tocada.

A categoria samba de roda funciona, portanto, como um discurso institucional que se ativa sobretudo em contextos de interação entre grupos 
"O MESMO SAMBA":

A PROFISSIONALIZAÇÂOO DOS SAMBAS DE CACHOEIRA E SUA REIFICAÇÂOO EM GRUPOS DE SAMBA DE RODA

sociais distintos: sambadores, representantes do governo, produtores culturais, etc. Mesmo quando sambas de vizinho são documentados dentro de seu contexto local, em registros oficiais, projetos culturais, ou materiais de divulgação, eles são denominados samba de roda. Ou seja, fora do universo cotidiano dos tocadores, a categoria samba de roda passa a designar tanto os sambas de vizinho como as tocadas. Tal categoria pode ser considerada como exponente de um discurso que pertence ao domínio da cultura com aspas ${ }^{l 7}$ nos termos de Manuela Carneiro da Cunha (2009). Neste sentido, ela funciona como uma metalinguagem; um discurso de um coletivo sobre si mesmo que permite a reificação de atividades cotidianas em categorias diferenciáveis e reconhecíveis em contextos de alteridade, permitindo e facilitando, por sua vez, a adoção de um novo conjunto de práticas e o trânsito destas e de seus sujeitos por contextos sociais variados.

É no contexto institucionalizado dos grupos de samba de roda e profissionalizado das tocadas que a categoria samba de roda ganha força e passa a ter uma aplicação cada vez mais ampla sem, contudo, confundir-se completamente com outras possibilidades de existência do samba. Assim, não é por casualidade que os coletivos profissionais dos tocadores tragam a categoria samba de roda como prefixo. O uso desta categoria comunica ao mundo das instituições públicas e privadas - tanto as locais quanto as de outras esferas - qual é a manifestação cultural a que aquele grupo se dedica. Na medida em que o tempo passa, os sambadores mais velhos morrem, os documentários, CDs, livros e programas de TV crescem em número, e um conjunto limitado de narrativas sobre o samba do Recôncavo Baiano se cristaliza (GRAEFF, 2016). O protagonista dessas narrativas é um tipo específico de sujeito coletivo, uma dentre as muitas formas possíveis de organização social dos tocadores: o grupo de samba de roda.

Não são, contudo, todos os tocadores e, muito menos, os modos de fazer samba que cabem na forma do grupo de samba de roda. Um exemplo

\footnotetext{
${ }^{17}$ Manuela Carneiro da Cunha (2009) subdivide a categoria antropológica de cultura em duas: a primeira corresponde genericamente à designação, de modo polissêmico e em muitos momentos da história da disciplina, de um conjunto de modos de pensamento e hábitos de grupos sociais; a segunda, a cultura com aspas, é uma metalinguagem; uma noção reflexiva que surge da apropriação da categoria de cultura pelos povos estudados pela Antropologia. A relação entre a cultura e a cultura com aspas é de mútua contaminação, o que não impede de analisá-las enquanto regimes discursivos distintos. A cultura com aspas opera, sobretudo, em um regime interétnico, tornando óbvios e reificados os traços diacríticos entre grupos sociais.
} 
disso é justamente seu Carlito, que abandonou o Samba de Roda Esmola Cantada no final dos anos 1990 e nunca mais integrou nenhum grupo de samba de roda. A gota d'água para sua decisão ocorreu durante um ensaio do grupo, no qual ele teria dito que não estava ali para aprender, mas sim para ensinar, como relatam diferentes pessoas. Esse episódio se deu justamente em um grupo com uma frequência de ensaios e formalidade maiores que dos demais, que não por acaso tem em sua coordenação musical um maestro de banda filarmônica educado em sistema de ensino formal de música. Entretanto, seu Carlito abandonou apenas o grupo, não deixando de tocar em outras ocasiões, como em suas obrigações religiosas da Festa da Santa Cruz, por exemplo. Isso demonstra que o grupo de samba de roda não suprime outros contextos e maneiras de fazer samba, embora crie tensões e contradições entre elas. As queixas de que o samba não é mais tão diverso, tão espontâneo ou mesmo tão divertido quanto antigamente não vêm apenas de seu Carlito, mas de vários tocadores mais velhos.

Podemos entender o processo de formação e profissionalização do samba como uma modulação entre os contextos tradicionais e os contextos das políticas culturais e do mercado de bens culturais, que tornam a categoria samba de roda, especialmente após a chancela do patrimonial do IPHAN e da UNESCO, onipresente. Sincronicamente, a categoria samba de roda opera um desvio sutil: ainda que exógena, seu significado é contíguo a várias categorias nativas dos tocadores de samba, dotando-a de uma relevante capacidade comunicacional. Diacronicamente, no entanto, seu uso sistemático tem a capacidade de reificá-la, apagando paulatinamente o desvio sutil operado por ela enquanto metadiscurso de emprego e significação específicos. A partir daí o termo samba de roda funciona como uma metonímia, tomando a parte pelo todo: o samba de roda profissionalizado e institucionalizado passa a representar, e de certa forma a substituir, as múltiplas possibilidades de existência do samba.

Para Gomes dos Anjos (2006), os coletivos afrobrasileiros absorvem formas de organização social brancas de um modo flexível que não sufoca as suas identidades negras; existe um movimento circular de fazer e desfazer identidades. Esta ideia se aplica ao samba de Cachoeira. Enquanto uma forma de organização social branca apropriada pelos coletivos afrobrasileiros locais, os grupos de samba de roda reduzem paulatinamente o universo de possibilidades do samba, tornando-o, aparentemente, mais homogêneo, pois 
"O MESMO SAMBA":

A PROFISSIONALIZAÇÂOO DOS SAMBAS DE CACHOEIRA E SUA REIFICAÇÂOO EM GRUPOS DE SAMBA DE RODA

reificado, mas sem sufocá-lo: os sambas de vizinho continuam a acontecer e mesmo a desenvolver uma maior variedade de possibilidades de circulação social para o samba. Por outro lado, o protagonismo crescente dos grupos de samba de roda em um contexto de eventos, políticas e projetos culturais cada vez mais institucionalizado, tem diminuído a variedade de tipos de samba feitos em Cachoeira, especialmente entre os sambadores mais jovens, que desconhecem vários gêneros de samba e técnicas tradicionais de toque e canto da região (Graeff, 2015).

\section{Conclusões}

Ao abordarmos os processos históricos de formação dos grupos de samba de roda em Cachoeira, fica clara sua relação direta com a mercantilização dos bens culturais da região. Entretanto, nota-se que tal mercantilização já existia em outros âmbitos; nos de domínio da elite branca, através das bandas de baile, das procissões católicas, das bandas filarmônicas, entre outros. Assim, a formação de grupos de samba, como evidencia o exemplo do Samba de Roda da Suerdieck, significa mais do que a assimilação de um formato externo de organização social. O grupo de samba se revela como um formato de fazer samba que permitiu às culturas afrodescendentes discriminadas se apropriarem de um território público autorizado até então apenas à elite.

Percebemos igualmente que os grupos não foram criados a partir do vácuo: trata-se da cristalização de uma história de longo prazo de envolvimento com o samba de uma família, uma comunidade ou um coletivo de devotos. O grupo é mais do que uma forma de organização social de ordem prática que permite a transformação do samba em espetáculo e a celebração de contratos para a prestação de serviços artísticos, tornando-se também uma síntese das próprias relações sociais e comunitárias dos sambadores.

Sendo assim, não é simplesmente um formato de grupo de música popular urbano que se impõe aos tocadores, pressionando-os a se adaptar às demandas de novos públicos intensificadas por medidas de salvaguarda. Os tocadores importam seus próprios valores e significados ao modo profissionalizado de sua prática: menos preocupados com o lucro do que com o sentido primordial do samba de comemoração inclusiva, eles levam às tocadas o máximo número de integrantes, não somente do grupo formal, mas de suas próprias comunidades religiosas e de bairro. Assim, a "vizinhança" 
afrodescendente do samba de vizinho se apropria do território limitado do palco à sua própria maneira.

O samba de roda, que vimos funcionar como um metadiscurso, representa mais do que uma chancela ou "etiqueta" da patrimonialização (Graeff, 2016). Trata-se de uma importante moeda de negociação entre diferentes interesses políticos, comerciais e mesmo estéticos, tendo no grupo de samba sua instituição facilitadora. O que hoje é referido como grupo de samba de roda opera uma formatação do samba que permite e enfatiza a comunicação com públicos externos ao contexto tradicional, tanto com audiências musicais como com agentes políticos e do âmbito da produção cultural e do turismo. O grupo de samba de roda funciona, portanto, como um eixo que articula a modulação da prática tradicional do samba para o metadiscurso do samba de roda, necessário para ampliar sua atuação social. Tal modulação demonstra um viés musical e performático, produzindo um estereótipo das diversas formas de fazer samba (GRAEFF, 2015; 2016) que reduz as formas tradicionais do samba de estivador, do samba de barravento, samba de verso, etc. ao formato samba de roda, marcado pela forma musical do samba corrido. Entretanto, seu viés operacional de sintetizar neste formato um metadiscurso capaz de comunicar a diversos públicos e agentes é fundamental na negociação da territorialidade política e econômica afrobrasileira.

Neste sentido, acreditamos que a profissionalização e patrimonialização do samba do Recôncavo Baiano, ao reificar suas práticas musicais, as reduz. Porém, tal redução diz respeito somente às suas formas tradicionais. Se, por um lado, as rupturas na transmissão oral entre gerações têm diminuído a variedade das formas antigas de fazer samba, como alegam os mais velhos, por outro, os novos espaços conquistados para a circulação do samba propiciam novas e heterogêneas formas de negociá-lo, comunicá-lo e, certamente, de praticá-lo. A ampliação dos espaços de atuação social dos sambas do Recôncavo Baiano ainda fará florescer novas dinâmicas de produção musical, de composição e de arranjo do que hoje ainda parece tratarse do "mesmo samba". 
"O MESMO SAMBA":

A PROFISSIONALIZAÇÂOO DOS SAMBAS DE CACHOEIRA E SUA REIFICAÇÂOO EM GRUPOS DE SAMBA DE RODA

\section{Referências}

BANDEIRA DE ALENCAR, Rívia R. (2010). O samba de roda na gira do patrimônio. Doutorado. Tese. Campinas, Universidade de Campinas.

BARICKMAN, Bert J. (2003). “E se a casa-grande não fosse tão grande? Uma freguesia açucareira do Recôncavo Baiano em 1835". Afro-Ásia, 29-30: 79-132

CARNEIRO DA CUNHA, Manuela. (2009). Cultura com aspas e outros ensaios. 1 a edição, São Paulo, Cosac Naify.

CARVALHO, José J. (2007). "Espetacularização e canibalização das culturas populares". In: Seminário de Políticas Públicas Para as Culturas Populares, II, Brasília, Ministério da Cultura: 78-101.

CSERMAK, Caio. (2017). "Quem vem lá sou eu. A política do samba de roda em Cachoeira-Bahia". REIA- Revista de Estudos e Investigações Antropológicas, ano 4, vol 4(1):45-70

DÖRING, Katharina. (2016). Cantador de chula: o samba antigo do Recôncavo. 1a edição, Salvador, Pinaúna.

FRAGA, Walter. (2014). Encruzilhadas da liberdade: histórias de escravos e libertos na Bahia (1870-1910). 2a edição, Rio de Janeiro, Civilização Brasileira.

GOMES DOS ANJOS, José C. (2006). No território da linha cruzada: a cosmopolítica afro-brasileira. 1a edição, Porto Alegre, UFRGS Editora.

GRAEFF, Nina. (2015). Os ritmos da roda: tradição e transformação no samba de roda. $1^{a}$ edição, Salvador, EDUFBA.

. 2016. "Samba de Roda as Heritage: From samba in the living room to 'Masterpiece of Humanity”', in: Die Tonkunst10/4, October 2016.

GRAEFF, Nina; OLIVEIRA PINTO, Tiago de (2007). "Música entre materialidade e imaterialidade: os tons-de-machete do Recôncavo Baiano". Mouseion, vol 01(11):72-97.

IPHAN - Instituto do Patrimônio e Artístico Nacional. (2006). Samba de roda do Recôncavo Baiano. 1a edição, Brasília, IPHAN.

MACHADO SILVA, Bruno G. (2018). Trânsitos da cultura popular: política pública, produção, difusão e salvaguarda nos encontros de culturas tradicionais. Doutorado. Tese. Brasília, Universidade de Brasília.

MACIEL, Danilo A. S. (2001). As alternativas turísticas na região do Recôncavo baiano no final da década de noventa. Bacharelado. Monografia. Salvador: Universidade Federal da Bahia. 
MARCELIN, Louis H. (1999). "A linguagem da casa entre os negros do Recôncavo Baiano”. Mana, vol 5(2): 31-60.

MARQUES, Francisca H. (2008). Festa da Boa Morte e Glória: ritual, música e performance. Doutorado. Tese. São Paulo, Universidade de São Paulo.

OLIVEIRA PINTO, Tiago de. (1991). Capoeira, Samba, Candomblé: afrobrasilianische Musik im Recôncavo, Bahia. Berlim, Museum für Völkerkunde.

ROQUE DE CASTRO, Janio. (2012). Da casa à praça pública: a espetacularização das festas juninas no espaço urbano. 1a edição, Salvador, EDUFBA.

RUBIM, Antonio A. C. (2010). Políticas culturais no governo Lula. 1a edição, Salvador, EDUFBA.

SANDRONI, Carlos (2010). "Samba de roda, patrimônio imaterial da humanidade". Revista de Estudos Avançados, vol 24(69): 373-388.

TRINDADE DA SILVA, Breno (2014). Políticas patrimoniais e salvaguarda: conflitos e estratégias no reconhecimento do samba de roda do Recôncavo Baiano. Mestrado. Dissertação. Salvador, Universidade Federal da Bahia.

TURINO, Tomas. (2008). Music as social life: the politics of participation. $1^{\text {a }}$ edição, Chicago, University of Chicago Press.

VATIN, Xavier. (2008). “O desenvolvimento do 'turismo 'étnico' na Bahia: o caso da cidade de Cachoeira”. Trabalho apresentado na 26a. Reunião Brasileira de Antropologia, realizada entre os dias 01 e 04 de junho de 2008, Porto Seguro, Bahia, Brasil

WADDEY, Ralph. (1980). “'Viola de Samba' and 'Samba de Viola' in the Recôncavo of Bahia (Brazil) part I". Latin American Music Review, 1:196-212

Recebido em: 31/10/2018

Aprovado em: 04/12/2018 